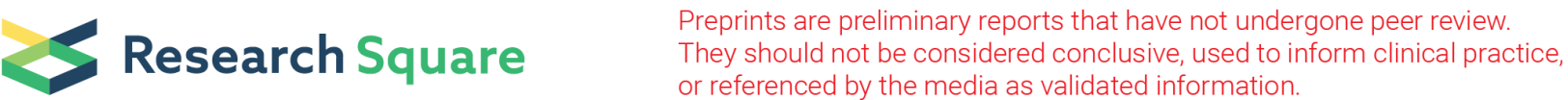

\section{Propylimidazole Functionalized Coumarin Derivative as Dual Responsive Fluorescent Chemoprobe for Picric Acid and Fe3+ Recognition: DFT and Natural Spring Water Applications}

Şükriye Nihan KARUK ELMAS ( $\nabla$ snihankaruk@gmail.com )

Karamanoglu Mehmetbey Universitesi https://orcid.org/0000-0002-1661-5902

Abdurrahman Karagoz

Karamanoglu Mehmetbey University: Karamanoglu Mehmetbey Universitesi

Fatma Nur Arslan

Karamanoglu Mehmetbey University: Karamanoglu Mehmetbey Universitesi

Ibrahim Yilmaz

Karamanoğlu Mehmetbey Üniversitesi: Karamanoglu Mehmetbey Universitesi

\section{Research Article}

Keywords: Fluorescent sensor, Picric acid, Iron, Coumarin, DFT, Natural water

Posted Date: November 10th, 2021

DOI: https://doi.org/10.21203/rs.3.rs-1039748/v1

License: (c) (1) This work is licensed under a Creative Commons Attribution 4.0 International License.

Read Full License 


\section{Abstract}

A propylimidazole functionalized coumarin derivative (IPC) was fabricated for the first time and applied as a dual responsive fluorescent chemoprobe for sensitive and selective recognitions of picric acid (PA) and $\mathrm{Fe}^{3+}$. Strong fluorescence quenching phenomena of the IPC were observed in $\mathrm{H}_{2} \mathrm{O} / \mathrm{ACN}(5 / 95, \mathrm{v} / \mathrm{v})$ medium $\left(\lambda_{\mathrm{em}}=408 \mathrm{~nm}\right)$ upon the additions of $\mathrm{Fe}^{3+}$ or PA. The fabricated dual responsive IPC offered good selectivity and sensitivity with the low limit of detection values $\left(0.92 \mu \mathrm{M}\right.$ for PA and $0.22 \mu \mathrm{M}$ for $\left.\mathrm{Fe}^{3+}\right)$ lower than the acceptable amounts of $\mathrm{Fe}^{3+}$ and PA by the international official authorities. The interaction phenomena of IPC with PA and $\mathrm{Fe}^{3+}$ based on the findings of a range of experiments were considered and DFT computations were done to verify their recognition mechanisms. The sensing phenomena of IPC towards PA (1:1) and Fe ${ }^{3+}$ (3:1) were confirmed by the MALDI TOF-MS, FT-IR, ${ }^{1} \mathrm{H}-\mathrm{NMR}$ titration and Job's methods. Furthermore, the compound IPC was effectively applied as a fluorescent sensor for $\mathrm{Fe}^{3+}$ and PA detection in real natural spring water samples.

\section{Introduction}

Fluorescent sensor technology has attracted extensive interestedness of researchers for trace analyte detection in recent years due to their advantages; such as operational/instrumental simplicity, portability, cost efficiency, excellent sensitivity/selectivity, ease of visual detection and fast signal processing [1-3]. Fluorescent organic substances have been extensively utilized for the design of fluorescent sensors/probes to recognize a wide range of environmentally and biologically important analyte like heavy metal ions/cations, anions, thiols, amino acids and nitro aromatic compounds [4]. Out of different nitro aromatic compounds, picric acid (PA; 2,4,6-trinitrophenol, TNP) is commonly utilized in blasting, manufacturing and chemical industries due to its better-quality explosiveness [5-8]. PA is known as a more influential secondary explosive substance than its structural related compounds like $p$ dinitrobenzene ( $p$-DNB), 2,4-dinitrotoluene (DNT) and trinitrotoluene (TNT) and is also defined as a threat to public security and human health. Due to its extremely explosive nature, it could easily be employed by terrorists for illegal activities [9]. Moreover, it could induce fatal diseases like anemia, cancer, faintness, acute scratchiness and allergic reactions of the skin, eye irritation and damage to the functions of kidney and liver and does not degrade easily in nature $[1,10,11]$. On the other hand, highly sensitive and selective recognitions of heavy metal ions in trace level with fluorescent organic compounds have been great interest because the fact that they have pivotal roles in various environmental and biological processes. For instance, $\mathrm{Fe}^{3+}$ has vital roles in many living systems like electron transfer, oxygen uptake and transportation. Its superabundance (hyperferremia) in the body would injure bio-systems and induces various failures of limbs such as the heart, liver and kidney; as a result of producing reactive oxygen species. In the meantime, its absence (hypoferremia) could result into to a number of critical diseases such as diabetes, insomnia, anemia diseases, and it induces iron homeostasis that is an important matter for the progression of Parkinson's, Huntington's and Alzheimer's diseases [12-15]. Thus; there is a great need to develop new analytical methodologies for the selective and sensitive recognition of PA and $\mathrm{Fe}^{3+}$. 
To date, several analytical methods have been developed for the recognition of PA and $\mathrm{Fe}^{3+}$, for instance, inductively coupled plasma-optical emission spectrometry (IPC-OES), ion chromatography (IC), atomic absorption spectroscopy (AAS), high-pressure liquid chromatography (HPLC), etc. These methods have some drawbacks, such as they have need of sophisticated instruments, specialized personnel, laborious sample pre-treatment procedures and usage of costly chemical regents. To keep away from these drawbacks, fluorescent sensing systems have been recently developed due to their superior advantages mentioned above $[7,16-18]$. However, the literatures based upon to fabricate dual responsive fluorescent chemoprobes for the recognition of both $\mathrm{PA}$ and $\mathrm{Fe}^{3+}$ with high selectivity and sensitivity, are still rare [10, 19-21]. Therefore, the need is great for more fluorescent chemoprobes able to detect the PA and $\mathrm{Fe}^{3+}$ in real-time and reliably.

Herein, a new propylimidazole functionalized coumarin compound, $\mathrm{N}-(3-(1 \mathrm{H}-$ imidazol-1-yl)propyl)2-oxo-2H-chromene-3-carboxamide (IPC) was prepared and utilized as a dual responsive fluorescent chemoprobe for the detection of PA and $\mathrm{Fe}^{3+}$. The optical properties and responses of IPC towards PA and $\mathrm{Fe}^{3+}$ in $\mathrm{H}_{2} \mathrm{O} / \mathrm{ACN}(5 / 95, \mathrm{v} / \mathrm{v})$ media were determined. DFT computations were done to confirm the electronic and geometrical structural characteristics of IPC and its complexes. Moreover, IPC was used for the sensitive detection of PA and $\mathrm{Fe}^{3+}$ in real natural spring water samples.

\section{Materials And Methods}

\subsection{Chemicals and instrumentations}

All chemical reagents and solvents were bought from commercial suppliers (Sigma Aldrich, Thermo Fisher Scientific and VWR International Chemicals) and used directly. Merck Milli-Q®7003/05/10/15 water purification machine in our laboratory was used to obtain ultra high-quality water, $18.2 \Omega . \mathrm{cm}$ (Darmstadt, Germany). Nitro aromatic explosives [4-Nitrobenzoyl chloride (NBC), 3,5-Dinitrobenzoic acid (DNBA), 4-Bromo-3-nitrobenzoic acid (BNBA), 2,4-Dinitrotoluene (DNT), 1-Chloro-2,4-dinitrobenzene (CDNB), 2,5-Dibromonitrobenzene (DBNB), Nitrobenzene (NB) and 2,4,6-trinitrophenol (PA, picric acid)] and perchloride cation salts $\left(\mathrm{K}^{+}, \mathrm{Ag}^{+}, \mathrm{Cu}^{2+}, \mathrm{Cd}^{2+}, \mathrm{Zn}^{2+}, \mathrm{Fe}^{2+}, \mathrm{Hg}^{2+}, \mathrm{Al}^{3+}\right.$ and $\left.\mathrm{Fe}^{3+}\right)$ were used under this study.

${ }^{1} \mathrm{H}$-NMR spectra were gained on a Bruker-DPX $600 \mathrm{MHz}$ (Massachusetts CA, USA) NMR spectrometers. Infrared spectra were recorded on a Spectrum-100 spectrometer with ATR accessory (Perkin Elmer Inc., MA, Wellesley, USA). Mass data were acquired on a Bruker Microflex ${ }^{\text {TM }}$ LT MALDI TOF-MS system (Massachusetts, CA, USA). Fluorescence studies were recorded on an Agilent Technologies Cary Eclipse fluorescence spectrometry (Santa Clara, California, USA). $\mathrm{pH}$ measurements were performed by using a benchtop pH-meter (Apera Instruments, Columbus, USA).

\subsection{Synthesis protocol of IPC}


Briefly, the compound $\mathbf{A}$ was synthesized according to the previous literature [22]. Then, the compound $\mathbf{A}$ (107 mg, $0.517 \mathrm{mmol}$ ) was added to a solution of 1-(3-aminopropyl)imidazole (64.61 $\mathrm{mg}, 0.517 \mathrm{mmol}$ ) in acetonitrile (MeCN, $10.0 \mathrm{~mL})$. The reaction mixture was stirred at it for $2 \mathrm{~h}$, and then the precipated was occurred. The obtained product was filtered by washing several times with MeCN (Scheme S1). Yield: 30 \%; FT-IR (ATR*solid) $\left(v, \mathrm{~cm}^{-1}\right)$ : 3139, 3026, 2981 and 1724; ${ }^{1} \mathrm{H}$ NMR (DMSO- $\left.d_{6}, 600 \mathrm{MHz}\right): \delta(\mathrm{ppm}) 8.73$ $(\mathrm{s}, 1 \mathrm{H}), 8.66(\mathrm{~s}, 1 \mathrm{H}), 8.58(\mathrm{~s}, 2 \mathrm{H}), 7.90(\mathrm{~d}, 1 \mathrm{H}), 7.71(\mathrm{t}, 2 \mathrm{H}), 7.58(\mathrm{~s}, 1 \mathrm{H}), 7.47(\mathrm{~s}, 1 \mathrm{H}), 4.17(\mathrm{t}, 2 \mathrm{H}), 2.74(\mathrm{t}$, $2 \mathrm{H}), 2.02(\mathrm{~m}, 2 \mathrm{H})$; Calculated MALDI TOF-MS: $\mathrm{C}_{16} \mathrm{H}_{15} \mathrm{~N}_{3} \mathrm{O}_{3}: 297.11$, Found MALDI TOF-MS: 298.526.

\subsection{Fluorescence studies of IPC}

For the fluorescence sensing studies, $1 \times 10^{-2} \mathrm{M}$ stock solution of the chemoprobe IPC was prepared and then it was diluted to $50 \mu \mathrm{M}$ in $\mathrm{H}_{2} \mathrm{O} / \mathrm{ACN}(5 / 95, \mathrm{v} / \mathrm{v})$ media. The stock solutions of nitro aromatic explosives (NBC, DNBA, BNBA, DNT, CDNB, DBNB, NB and PA) and metal ions $\left(\mathrm{K}^{+}, \mathrm{Ag}^{+}, \mathrm{Cu}^{2+}, \mathrm{Cd}^{2+}, \mathrm{Zn}^{2+}\right.$, $\mathrm{Fe}^{2+}, \mathrm{Hg}^{2+}, \mathrm{Al}^{3+}$ and $\left.\mathrm{Fe}^{3+}\right)$ were prepared as $1 \times 10^{-2} \mathrm{M}$. The spectra of $\mathrm{PA}$ and $\mathrm{Fe}^{3+}$ were gathered from the emission region of $340-800 \mathrm{~nm}\left(\lambda_{e x}=330 \mathrm{~nm}, \lambda_{e m}=408 \mathrm{~nm}\right.$, slit widths 10.0 and $\left.20.0 \mathrm{~nm}\right)$. Titration plots were constructed by plotting the emission intensities at $408 \mathrm{~nm}$. For the selectivity studies, the same equivalents of 7 kinds of nitro aromatic explosives (50.0 eqv.) and 8 kinds of metal ions (50.0 eqv.) were employed into the chemoprobe IPC solution. All the fluorescence measurements were performed at least three times.

\subsection{Computational studies}

The molecular structures and HOMO/LUMO levels of the IPC and its complexes (IPC-PA and IPC- $\mathrm{Fe}^{3+}$ ) were gained with the gas phase, by using DFT computations through the employ of Gaussian-09 $\left[B 3 L Y P / L A N L 2 D Z\right.$ (for PA and $\mathrm{Fe}^{3+}$ ) and 6-31G $(d, p)($ for $\left.C, H, N, O)\right]$ and GaussView-5.0.8 software packages (Gaussian, Inc., Wallingford CT, UK).

\subsection{Natural spring water analysis}

Natural spring water samples were collected from local water resources in Konya City. The samples were analyzed without sample pre-treatment; just they were centrifugated at $10.000 \mathrm{rpm}$ for $3 \mathrm{~min}$. For the quantification analyses, the standard addition method was applied with two different-concentrations ( 0.10 and $0.20 \mu \mathrm{mol} . \mathrm{L}^{-1}$ ) of PA and $\mathrm{Fe}^{3+} .3 \mathrm{~mL}$ of the IPC sensing solution was transferred into quartzcuvette, and then $15.0 \mu \mathrm{L}$ sample was added twice into this solution. All the fluorescence measurements were performed at least three times and the statistical calculations were done.

\section{Results And Discussion}

\subsection{Fabrication and characterization of IPC}

IPC was obtained as a white solid and well characterized using FT-IR, ${ }^{1} \mathrm{H}-\mathrm{NMR}$ and MALDI TOF-MS techniques (Fig S1-S3). ${ }^{1}$ H NMR spectrum shows a-hydrogen of coumarine and aliphatic peaks of 
propylimidazole groups clearly. In addition, $298.526(\mathrm{~m} / \mathrm{z})$ was observed at corresponding to IPC (chemical formula: $\mathrm{C}_{16} \mathrm{H}_{15} \mathrm{~N}_{3} \mathrm{O}_{3}$ ) in the mass spectrum.

\subsection{Fluorescence sensing studies of IPC}

The effect of different solvents on the emission intensity of IPC was studied. For this purpose, the emission intensities were obtained upon excitation at $330 \mathrm{~nm}$ for the chemoprobe IPC prepared in acetonitrile $(\mathrm{ACN})$, methanol $(\mathrm{MeOH})$, ethanol $(\mathrm{EtOH})$, dimethylformamide $(\mathrm{DMF})$, water $\left(\mathrm{H}_{2} \mathrm{O}\right)$, and dimethylsulfoxide (DMSO) (Fig S4). The maximum fluorescence of IPC was achieved at $408 \mathrm{~nm}$ as it was prepared in ACN. The influence of water percentage used in ACN on the fluorescence response was also studied for the IPC, IPC-PA and IPC- $\mathrm{Fe}^{3+}$. The differentiations of emission intensities between the chemoprobe IPC and its complexes were the most appropriate when the both volume ratio of $\mathrm{ACN} / \mathrm{H}_{2} \mathrm{O}$ was $95 / 5$. Thus, the solvent media of $\mathrm{H}_{2} \mathrm{O} / \mathrm{ACN}(5 / 95, \mathrm{v} / \mathrm{v})$ was employed for the further fluorescence measurements under this study.

To reveal the sensing ability of chemoprobe IPC, its response towards a pool of analyte including different nitro aromatic explosives (NBC, DNBA, BNBA, DNT, CDNB, DBNB, NB and PA) and metal ions ( $K^{+}$, $\mathrm{Ag}^{+}, \mathrm{Cu}^{2+}, \mathrm{Cd}^{2+}, \mathrm{Zn}^{2+}, \mathrm{Fe}^{2+}, \mathrm{Hg}^{2+}, \mathrm{Al}^{3+}$ and $\left.\mathrm{Fe}^{3+}\right)$ was determined in $\mathrm{H}_{2} \mathrm{O} / \mathrm{ACN}(5 / 95, \mathrm{v} / \mathrm{v})$ media (Figs. 1 and 2), with the help of fluorescence experiments. As seen from these figures, the chemoprobe IPC demonstrated high emission intensity at $408 \mathrm{~nm}$ upon excited at $330 \mathrm{~nm}$. The chemoprobe IPC depicted dramatic "turn off" response towards both PA explosive (Fig. 1a) and Fe ${ }^{3+}$ (Fig. 2a) over other studied analytes, within 30 seconds. Subsequently, emission titration studies of IPC were performed with the increasing concentrations of PA (0-20.0 equiv.) (Fig. 1b) and Fe ${ }^{3+}(0-20.0$ equiv.) (Fig. 2b). Upon the adding of PA into a solution of chemoprobe IPC $(50 \mu \mathrm{M})$, the emission intensity progressively quenched due to the $\pi-\pi$ stacking and deprotonation phenomena [23] and it arrived a minimum intensity level after the adding of 20.0 equiv. of PA. On the contrary, after the addition of different amounts of $\mathrm{Fe}^{3+}$, the emission intensity of IPC quenched because of the paramagnetic quenching affect with the transferring of energy and/or electron, which is known as "ligand-metal charge transfer mechanism (LMCT)". The fluorescence intensity was reach a stable value after the concentration of $\mathrm{Fe}^{3+}$ reached 20.0 equiv. (Fig. 2b) $[15,24,25]$.

From the findings of fluorescence titration studies, the detection limits (LOD) of chemoprobe IPC for PA and $\mathrm{Fe}^{3+}$ were computed by fluorescence alterations on the basis of $3 \sigma / k$ equation; where " $\sigma$ " is deviation of the blank emission intensity and " $k$ " is slope of linear calibration graph. They were found to be $0.92 \mu \mathrm{M}$ for PA and $0.22 \mu \mathrm{M}$ for $\mathrm{Fe}^{3+}$, which is less than the daily uptake level of iron ion $\left(2 \mathrm{mg} \cdot \mathrm{L}^{-1}\right)$ suggested by the WHO [15]. These titration data were also employed to compute the association constants $(\log K)$ of IPC-PA and IPC- $\mathrm{Fe}^{3+}$ complexes, and they were found to be $6.72 \times 10^{2} \mathrm{M}^{-1}$ for PA and $3.62 \mathrm{M}^{-1 / 3}$ for $\mathrm{Fe}^{3+}$ on the basis of Benesi-Hildebrand equation (Fig. 3) [26-28]. Thus, these findings recommended that the chemoprobe IPC has a great potential of recognition quantitatively unidentified concentrations of PA or $\mathrm{Fe}^{3+}$ and could be utilized for the sensitive recognition of $\mathrm{PA}$ and $\mathrm{Fe}^{3+}$ in $\mathrm{H}_{2} \mathrm{O} / \mathrm{ACN}(5 / 95, \mathrm{v} / \mathrm{v})$ media. The 
sensing properties of the chemoprobe IPC are also comparable to those of some dual-responsive fluorescent probes for PA and $\mathrm{Fe}^{3+}$, which reveals that our chemoprobe system has significant improvements (Table 1).

To use the chemoprobe IPC as a selective fluorescent sensor for $\mathrm{PA}$ and $\mathrm{Fe}^{3+}$, the impacts of competing nitro aromatic explosives (NBC, DNBA, BNBA, DNT, CDNB, DBNB, NB and PA) and metal ions $\left(\mathrm{K}^{+}, \mathrm{Ag}^{+}\right.$, $\mathrm{Cu}^{2+}, \mathrm{Cd}^{2+}, \mathrm{Zn}^{2+}, \mathrm{Fe}^{2+}, \mathrm{Hg}^{2+}, \mathrm{Al}^{3+}$ and $\mathrm{Fe}^{3+}$ ) have been also studied. As seen from Fig. 4a, the emission quenching was observed for the mixtures of PA with other nitro aromatic explosives was similar to that stimulated by PA alone; therefore, the presence of competing explosives could not make interference on the recognition of PA. Likewise, $\mathrm{Fe}^{3+}$ sensing system in $\mathrm{H}_{2} \mathrm{O} / \mathrm{ACN}(5 / 95, \mathrm{v} / \mathrm{v})$ media was not influenced by a pool of metal ions (Fig. 4b). The competition studies showed that fluorescence response of the chemoprobe IPC toward PA or $\mathrm{Fe}^{3+}$ was not interfered by the studied competing analytes; therefore, IPC could be used as a "turn-off" fluorescent chemoprobe for the recognitions of both PA and Fe ${ }^{3+}$.

The response time is another critical parameter for a new designed chemoprobe in real applications. As seen from Fig S5, the fluorescence quenching for PA and Fe ${ }^{3+}$ was occurred only within just 30 seconds, and at their fluorescence intensities were reached to equilibrium at same response time. Thus, a response time was decided on 30 seconds for the following experiments and the chemoprobe IPC depicted an excellent response time towards $\mathrm{PA}$ and $\mathrm{Fe}^{3+}$ respecting the formerly developed a lot of fluorogenic dual chemoprobes [10, 19-21].

\subsection{Binding mechanisms of IPC towards PA and $\mathrm{Fe}^{3+}$}

To understand the binding stoichiometry of the complexes between IPC and PA/Fe ${ }^{3+}$, the MALDI TOFMS, FT-IR and Job's plot methods were applied. The stoichiometric ratios of chemoprobe IPC toward $\mathrm{Fe}^{3+}$ were found to be 3:1. To determine the binding stoichiometry of IPC-Fe ${ }^{3+}$ complex, Job's plot study was performed (Fig S6). The fluorescence intensities at $408 \mathrm{~nm}$ are graphed against the molar fractions of the chemoprobe IPC. The maximum spot was monitored at mole fraction of 0.75 for $\mathrm{Fe}^{3+}$ and this result have showed that it was 3:1 stoichiometry of the binding mode of IPC- $\mathrm{Fe}^{3+}$. In addition, it is clearly observed that the $\mathrm{N}-\mathrm{H}$ peak of the chemosensor IPC, which was present at $3259 \mathrm{~nm}$, disappeared in the infrared spectrum of the complex. The $\mathrm{C}=0$ peak of the chemosensor IPC was shifted from $1722 \mathrm{~nm}$ to $1709 \mathrm{~nm}$ (Fig S7). Also, The MALDI TOF-MS data also confirms the 3:1 of binding stoichiometry between the chemoprobe IPC and $\mathrm{Fe}^{3+}$, because the peaks at $\mathrm{m} / \mathrm{z}=298.526$ and $\mathrm{m} / \mathrm{z}=944.219$ correspond to the [chemoprobe IPC $+\mathrm{H}^{+}$] and [chemoprobe IPC $+\mathrm{Fe}^{3+}+\mathrm{H}^{+}$], respectively (Fig S8). The stoichiometric ratios of chemoprobe IPC towards PA were found to be 1:1 (Fig S6). To understand the binding stoichiometry of IPC- $\mathrm{Fe}^{3+}$ complex, Job's plot study was performed. The maximum spot was monitored at mole fraction of 0.5 for PA and this result have showed that it was 1:1 stoichiometry of the binding mode of IPC-PA. Also, ${ }^{1} \mathrm{H}$-NMR measurements were performed to obtain an insight into the interaction mechanism between IPC and PA. As depicted in Fig S9, the slight peak was shifted up-field in 
the presence of PA. Therefore, the formation of $\pi-\pi$ stackking and the intermolecular $\mathrm{H}$-bonds between IPC and PA caused the quenching of fluorescence intensity $[5,23]$.

\subsection{Theoretical computations}

Theoretical computations of the chemoprobe IPC and its complexes have been done to obtain their HOMO-LUMO energy levels. The orbital energies were computed using Gaussian-09 [B3LYP/6-31G $(d, p)$ (for IPC and IPC-PA) and LANL2DZ (for IPC-Fe $\left.e^{3+}\right)$ ] and GaussView-5.0.8 software packages. To confirm the suggested interaction pathway of the chemoprobe IPC toward PA, DFT calculation was performed based on the reported study [5]. The optimal structure of IPC-PA displayed intermolecular hydrogen bonding between IPC and PA due to $\pi-\pi$ interactions (Fig. 5). As depicted in Fig. 5, the computed energy gaps between HOMO and LUMO orbitals of IPC, IPC-PA and IPC- $\mathrm{Fe}^{3+}$ were found as $3.32,2.19$ and $0.7 \mathrm{eV}$, respectively, showing good interactions. Therefore, these findings revealed that the interaction of IPC towards PA and $\mathrm{Fe}^{3+}$ stabilizes the systems as evident from the lower HOMO-LUMO energy gaps of the complexes compared to IPC (Fig. 5).

\subsection{Natural spring water application}

In the last part of study, the applicability of the developed fluorescence chemoprobe system for the recognition of $\mathrm{PA}$ or $\mathrm{Fe}^{3+}$ in natural spring water samples was tested. For real water sample measurements, the samples were spiked with known concentrations $\left(0.10\right.$ and $\left.0.20 \mathrm{~mol}^{-\mathrm{L}^{-1}}\right)$ of PA or $\mathrm{Fe}^{3+}$, according to the standard addition method. After the adding of PA or $\mathrm{Fe}^{3+}$ into the solution of chemoprobe IPC, their fluorescence intensities were recorded. The findings were given in Table 2, and the recovery values of $\mathrm{PA}$ and $\mathrm{Fe}^{3+}$ were between 93.01 and $112.54 \%$ with the lower relative standard deviation (RSD) values. Thus, these findings revealed that the chemoprobe IPC system could specifically and accurately labor to recognize $\mathrm{PA}$ or $\mathrm{Fe}^{3+}$ in natural spring waters.

\section{Conclusion}

In summarize, a new of dual-responsive fluorescence chemoprobe (IPC) based on propylimidazole functionalized coumarin structure for the recognition of $\mathrm{PA}$ and $\mathrm{Fe}^{3+}$ has been successfully developed. The IPC revealed "on-off" fluorescence responses towards PA and $\mathrm{Fe}^{3+}$ at $408 \mathrm{~nm}$ within only 30 seconds in $\mathrm{H}_{2} \mathrm{O} / \mathrm{ACN}(5 / 95, \mathrm{v} / \mathrm{v})$ media. The LOD values for PA and $\mathrm{Fe}^{3+}$ were found to be $0.92 \mu \mathrm{M}$ and $0.22 \mu \mathrm{M}$, respectively, which are satisfactorily low to permit the recognition of these analytes in realistic applications. The stoichiometry of the complexes [IPC-PA (1:1) and IPC- $\mathrm{Fe}^{3+}$ (3:1)] was identified by MALDI TOF-MS, FT-IR, ${ }^{1} \mathrm{H}-\mathrm{NMR}$ titration and Job's plot experiments. The binding mechanism of IPC toward PA or $\mathrm{Fe}^{3+}$ was also supported by DFT computation study. Furthermore, the chemoprobe IPC was employed for the detecting PA or $\mathrm{Fe}^{3+}$ in natural spring waters with good recovery values. Therefore, these promising findings will make a great contribution to researchers studying nitro aromatic explosives and metal ions in different systems.

\section{Declarations}


Author's Contributions. All authors contributed in the planning, editing and writing of the manuscript.

Conflicts of interest. We declare that we have no known competing financial interests or personal relationships that could have appeared to influence the work reported in this paper.

Ethical Approval. All procedures performed in studies involving human participants were in accordance with the ethical standards of the institutional and/or national research committee and with the 1964 Helsinki Declaration and its later amendments or comparable ethical standards.

Informed Consent. Informed consent was obtained from all individual participants included in the study.

Funding. This study was supported by the KMU with the financial support (KMU BAP-Grant Number: 06$M-20)$.

Data Availability. The data sets generated during the current study are available from the corresponding author on reasonable request.

Consent to participate. Not applicable.

Consent for publication. Not applicable.

\section{References}

1. Sharma S, Dubey G, Sran BS, et al (2019) Fabrication of a Hydrazone-Based Al(III)-Selective " TurnOn " Fluorescent Chemosensor and Ensuing Potential Recognition of Picric Acid. ACS Omega 4:1852018529 . doi: $10.1021 /$ acsomega.9b02132

2. Celestina JJ, Tharmaraj P, Sheela CD, Shakina J (2021) Anthracene based selective Co ( II ) colorimetric and fluorescent sensor for cytotoxicity studies and real sample analysis. J Lumin 239:118359 . doi: 10.1016/j.jlumin.2021.118359

3. Cai Z, Zhu R, Zhang S, et al (2021) A highly sensitive and selective " turn off " fluorescent sensor based on water soluble copper nanoclusters for morin and temperature sensing. J Lumin 236:118108

4. Saravana Kumar S, Selva Kumar R, Ashok Kumar SK (2020) An "Off-On-Off" type fluorescent chemosensor for the relay detection of $\mathrm{Zn2}+$ and $\mathrm{H} 2 \mathrm{PO} 4-$ in aqueous environment. Inorganica Chim Acta 502:119348 . doi: https://doi.org/10.1016/j.ica.2019.119348

5. Pandith A, Kumar A, Lee JY, Kim HS (2015) 9-Anthracenecarboxamide fluorescent probes for selective discrimination of picric acid from mono- and di-nitrophenols in ethanol. Tetrahedron Lett 56:7094-7099 . doi: 10.1016/j.tetlet.2015.11.017

6. Roy B, Bar AK, Gole B, Mukherjee PS (2013) Fluorescent Tris-Imidazolium Sensors for Picric Acid Explosive. J Org Chem 78:1306-1310 
7. Ahmed R, Ali A, Ahmad M, et al (2020) Phenanthroimidazole derivatives as Chemosensor for Picric Acid: A First Realistic Approach. New J Chem 44:20092-20100 . doi: 10.1039/D0NJ03422C.Volume

8. Li W, Zhou H, Nawaz MAH, et al (2020) A perylene monoimide probe based fluorescent micelle sensor for the selective and sensitive detection of picric acid. Anal Methods 12:5353-5359

9. Li J, Zhuang X, Zhang N, et al (2019) Synthesis and characterization of a luminescent $\mathrm{Ni}(\mathrm{II})$ compound based on tpt and $\mathrm{m}-\mathrm{H} 2 \mathrm{bdc}$ detecting picric acid and chromate anions in aqueous. Inorganica Chim Acta 497:119096 . doi: https://doi.org/10.1016/j.ica.2019.119096

10. Arockiam JB, Ayyanar S (2017) Benzothiazole, pyridine functionalized triphenylamine based fluorophore for solid state fluorescence switching , Fe $3+$ and picric acid sensing. Sensors Actuators B Chem 242:535-544 . doi: 10.1016/j.snb.2016.11.086

11. Rajalakshmi AV, Palanisami N (2020) Y-shaped ferrocene/non-ferrocene conjugated quinoxalines for colorimetric and fluorimetric detection of picric acid. Spectrochim Acta Part A Mol Biomol Spectrosc 228:117812

12. Hossain SM, Dam GK, Mishra S, Singh AK (2020) Nano-Molar Level Fluorogenic and OxidationState Selective Chromogenic Dual Reversible Chemosensor for Multiple Targets Cu2+/S2- and Fe3+/Fion Sayed. New J Chem 44:15186-15194 . doi: 10.1039/D0NJ02777D

13. David $\mathrm{Cl}$, Bhuvanesh N, Jayaraj $\mathrm{H}$, et al (2020) Experimental and Theoretical Studies on a Simple S - S-Bridged Dimeric Schi ff Base: Selective Chromo-Fluorogenic Chemosensor for Nanomolar Detection of Fe 2+ \& Al 3+ lons and Its Varied Applications. ACS Omega 5:3055-3072 . doi:

10.1021/acsomega.9b04294

14. Yun JY, Chae JB, Kim M, et al (2019) A multiple target chemosensor for the sequential fluorescence detection of $\mathrm{Zn} 2+$ and $\mathrm{S} 2-$ and the colorimetric detection of $\mathrm{Fe} 3+/ 2+$ in aqueous media and living cells. Photochem Photobiol Sci 18:166-176 . doi: 10.1039/c8pp00408k

15. Elmas SNK, Gunay IB, Genc HN, et al (2020) A tetraoxacalix[2]arene[2]triazine based fluorogenic probe for the sensing of $\mathrm{Fe} 3+$ : Computational and living-cell imaging applications. J Photochem Photobiol A Chem 403:112848 . doi: 10.1016/j.jphotochem.2020.112848

16. Li Y-J, Yun-Fei Zhang, You-Ming Zhang, et al (2020) Tripodal naphthalimide assembled novel AIE supramolecular fluorescent sensor for rapid and selective detection of picric acid. Dye Pigment 181:108563

17. Parvathy PA, R. Dheepika, R. Abhijnakrishna, et al (2020) Fluorescence quenching of triarylamine functionalized phenanthroline-based probe for detection of picric acid. J Photochem Photobiol A Chem 401:112780 
18. Yan N, Jiale Song, Fengyan Wang, et al (2019) Pyrenoviologen-based fluorescent sensor for detection of picric acid in aqueous solution. Chinese Chem Lett 30:1984-1988

19. Han Y, Zhao J, Yang H, et al (2020) Synthesis of new fl uorene compounds for highly selective sensing of picric acid , Fe3+ and L -arginine. J Mol Struct 1217:128395 . doi:

10.1016/j.molstruc.2020.128395

20. Roja SS, Shylaja A, Kumar R (2020) Phenothiazine-Tethered 2-Aminopyridine-3-carbonitrile: Fluorescent Turn-Off Chemosensor for Fe3+ lons and Picric Acid. ChemistrySelect 5:2279-2283 . doi: $10.1002 /$ slct.201904425

21. Shylaja A, Rubina SR, Roja SS, Kumar RR (2020) Novel blue emissive dimethylfuran tethered 2aminopyridine-3-carbonitrile as dual responsive fluorescent chemosensor for $\mathrm{Fe} 3+$ and picric acid in nanomolar detection limit. Dye Pigment 174:108062 . doi: 10.1016/j.dyepig.2019.108062

22. Li T, Wang L, Lin S, et al (2018) Rational Design and Bioimaging Applications of Highly Specific "Turn-On" Fluorescent Probe for Hypochlorite. Bioconjug Chem 29:2838-2845 . doi:

10.1021/acs.bioconjchem.8b00430

23. Kundu BK, Pragti, Reena, et al (2019) Mechanistic and thermodynamic aspects of a pyrene-based fluorescent probe to detect picric acid. New J Chem 43:11483-11492 . doi: 10.1039/c9nj02342a

24. He W, Liu Z (2016) A fluorescent sensor for Cu2+ and Fe3+ based on multiple mechanisms. RSC Adv 64:1-9 . doi: 10.1039/C6RA09535F

25. Ma Y, Luo W, Quinn PJ, et al (2004) Design, Synthesis, Physicochemical Properties, and Evaluation of Novel Iron Chelators with Fluorescent Sensors. J Med Chem 47:6349-6362

26. Aydin D, Nihan S, Elmas K, et al (2021) An ultrasensitive " OFF - ON " fluorogenic sensor based on thiazole derivative for $\mathrm{Zn} 2+$ : Food supplement, water and bio - imaging applications. J Photochem Photobiol , A Chem 419:113459

27. Nihan S, Elmas K, Karagoz A, et al (2021) Fabrication and sensing properties of phenolphthalein based colorimetric and turn - on fluorogenic probe for $\mathrm{CO} 23$ detection and its living - cell imaging application. Talanta 226:122166 . doi: 10.1016/j.talanta.2021.122166

28. Nihan S, Elmas K, Dinckan S, et al (2021) A rhodamine based nanosensor platform for $\mathrm{Hg} 2+$ sensing in near - perfect aqueous medium: Smartphone, test strip and real sample applications. $J$ Photochem Photobiol , A Chem 421:113521

\section{Tables}

Table 1. Comparison of the chemoprobe IPC with some reported studies towards PA and $\mathrm{Fe}^{3+}$ 


\begin{tabular}{|c|c|c|c|c|c|c|}
\hline chemoprobe & $\begin{array}{c}\text { recognition } \\
\text { process }\end{array}$ & $\begin{array}{l}\text { solvent } \\
\text { system }\end{array}$ & LOD (M) & $\begin{array}{c}\text { binding } \\
\text { constant } \\
\left(M^{-x}\right)\end{array}$ & application & ref. \\
\hline & turn-off & DMSO & $\begin{array}{c}0.098 \times 10^{-6} \\
\quad(\text { for } \mathrm{PA}) \\
4.90 \times 10^{-6} \\
\left(\text { for } \mathrm{Fe}^{3+}\right)\end{array}$ & $\begin{array}{c}9.73 \times 10^{4} \\
(\text { for PA) } \\
3.49 \times 10^{3} \\
\left(\text { for } \mathrm{Fe}^{3+}\right)\end{array}$ & yes & {$[20]$} \\
\hline & turn-off & $\begin{array}{l}\mathrm{H}_{2} \mathrm{O} / \mathrm{EtOH} \\
(25 / 75, \mathrm{v} / \mathrm{v})\end{array}$ & $\begin{array}{c}6.90 \times 10^{-7} \\
(\text { for } \mathrm{PA}) \\
3.60 \times 10^{-7} \\
\left(\text { for } \mathrm{Fe}^{3+}\right)\end{array}$ & $\begin{array}{c}4.65 \times 10^{5} \\
(\text { for } \mathrm{PA}) \\
1.42 \times 10^{5} \\
\left(\text { for } \mathrm{Fe}^{3+}\right) \\
\end{array}$ & yes & [19] \\
\hline & turn-off & $\begin{array}{l}\mathrm{H}_{2} \mathrm{O} / \mathrm{MeOH} \\
(20 / 80, v / v)\end{array}$ & $\begin{array}{c}1.01 \times 10^{-4} \\
\text { (for PA) } \\
\text { colorimetric } \\
\text { for } \mathrm{Fe}^{3+}\end{array}$ & - & no & {$[10]$} \\
\hline & turn-off & $\begin{array}{l}\mathrm{H}_{2} \mathrm{O} / \mathrm{ACN} \\
(5 / 95, \mathrm{v} / \mathrm{v})\end{array}$ & $\begin{array}{l}0.92 \times 10^{-6} \\
(\text { for } \mathrm{PA}) \\
0.22 \times 10^{-6} \\
\left(\text { for } \mathrm{Fe}^{3+}\right)\end{array}$ & $\begin{array}{c}6.72 \times 10^{2} \\
(\text { for } \mathrm{PA}) \\
3.62 \\
\left(\text { for } \mathrm{Fe}^{3+}\right)\end{array}$ & yes & $\begin{array}{l}\text { this } \\
\text { study }\end{array}$ \\
\hline
\end{tabular}

Table 2. Fluorescence detection of PA and $\mathrm{Fe}^{3+}$ in natural spring waters by IPC 


\begin{tabular}{|c|c|c|c|c|}
\hline & $\begin{array}{l}\text { PA spiked }(\mu \mathrm{mol} \rrbracket \\
\left.\mathrm{L}^{-1}\right)\end{array}$ & $\begin{array}{l}\text { PA determined } \\
\left(\mu \mathrm{mol} \mathrm{ZL}^{-1}\right)\end{array}$ & $\begin{array}{l}\text { recovery } \\
(\%)\end{array}$ & $\begin{array}{l}\text { RSD }(\%) \\
(n=3)\end{array}$ \\
\hline \multirow[t]{3}{*}{ ultra pure water } & 0.00 & $0.0153 \pm 0.0003$ & & 1.64 \\
\hline & 0.10 & $0.1191 \pm 0.0032$ & 103.79 & 2.70 \\
\hline & 0.20 & $0.2133 \pm 0.0036$ & 99.02 & 1.69 \\
\hline \multirow{3}{*}{$\begin{array}{l}\text { natural spring water } \\
-1\end{array}$} & 0.00 & $0.0331 \pm 0.0010$ & & 3.02 \\
\hline & 0.10 & $0.1262 \pm 0.0025$ & 93.01 & 1.99 \\
\hline & 0.20 & $0.2510 \pm 0.0068$ & 108.91 & 2.71 \\
\hline \multirow{4}{*}{$\begin{array}{l}\text { natural spring water } \\
-2\end{array}$} & 0.00 & $0.0047 \pm 0.0001$ & & 2.12 \\
\hline & 0.10 & $0.1038 \pm 0.0025$ & 99.13 & 2.42 \\
\hline & 0.20 & $0.2141 \pm 0.0072$ & 104.71 & 3.37 \\
\hline & $\begin{array}{l}\mathrm{Fe}^{3+} \text { spiked }(\mu \mathrm{mol} \rrbracket \\
\left.\mathrm{L}^{-1}\right)\end{array}$ & $\begin{array}{l}\mathrm{Fe}^{3+} \text { determined }(\mu \mathrm{mol} \rrbracket \\
\left.\mathrm{L}^{-1}\right)\end{array}$ & $\begin{array}{l}\text { recovery } \\
(\%)\end{array}$ & $\begin{array}{l}\text { RSD }(\%) \\
(n=3)\end{array}$ \\
\hline \multirow[t]{3}{*}{ ultra pure water } & 0.00 & $0.0005 \pm 0.00001$ & & 2.12 \\
\hline & 0.10 & $0.1075 \pm 0.0012$ & 107.02 & 1.12 \\
\hline & 0.20 & $0.1974 \pm 0.0051$ & 98.47 & 2.60 \\
\hline \multirow{3}{*}{$\begin{array}{l}\text { natural spring water } \\
-1\end{array}$} & 0.00 & $0.0120 \pm 0.0003$ & & 2.21 \\
\hline & 0.10 & $0.1245 \pm 0.0030$ & 112.54 & 2.41 \\
\hline & 0.20 & $0.2088 \pm 0.0042$ & 98.39 & 1.99 \\
\hline \multirow{3}{*}{$\begin{array}{l}\text { natural spring water } \\
-2\end{array}$} & 0.00 & $0.0160 \pm 0.0003$ & & 1.65 \\
\hline & 0.10 & $0.1184 \pm 0.0042$ & 102.35 & 3.52 \\
\hline & 0.20 & $0.2355 \pm 0.0050$ & 109.73 & 2.14 \\
\hline
\end{tabular}

\section{Scheme}

Please see the Supplementary Files for the Scheme 1 and 2.

\section{Figures}




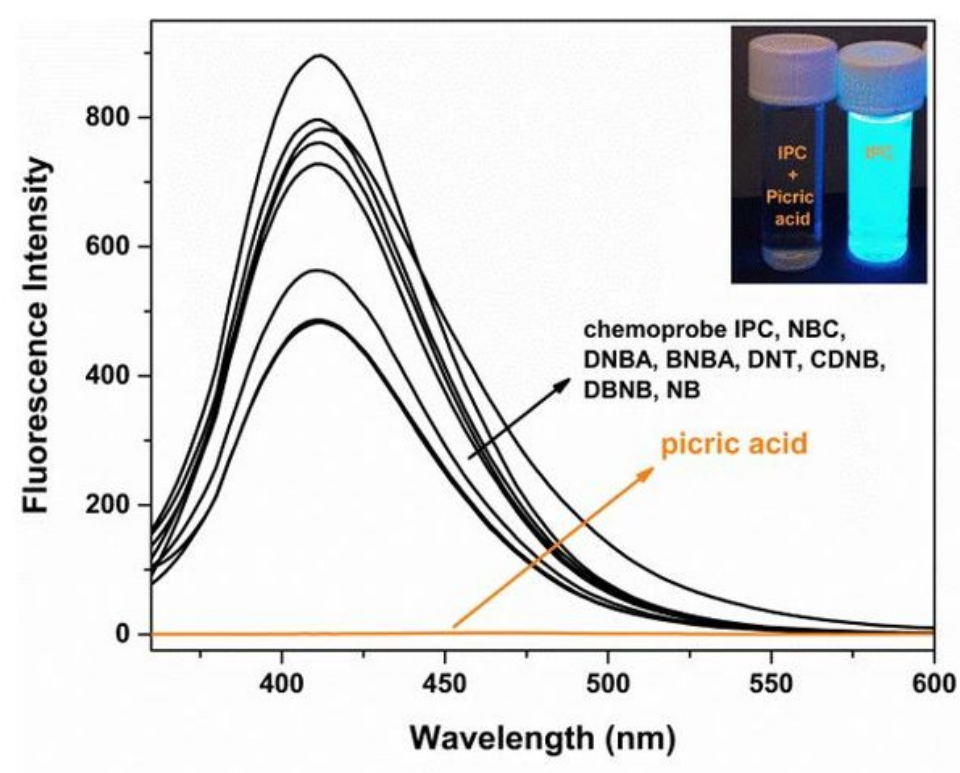

(a)

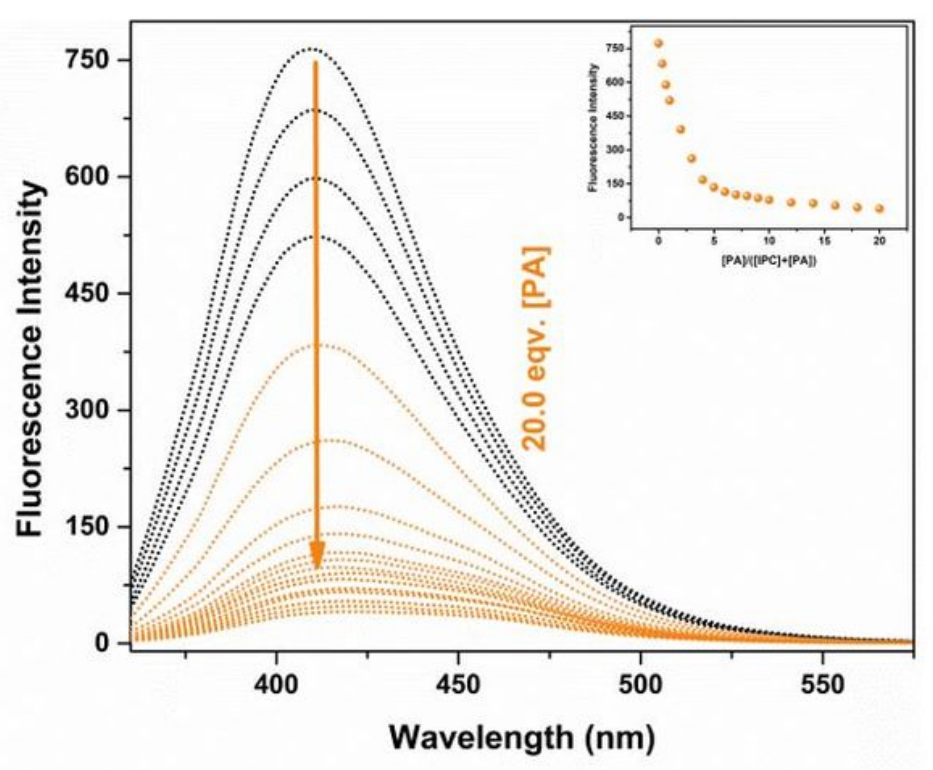

(b)

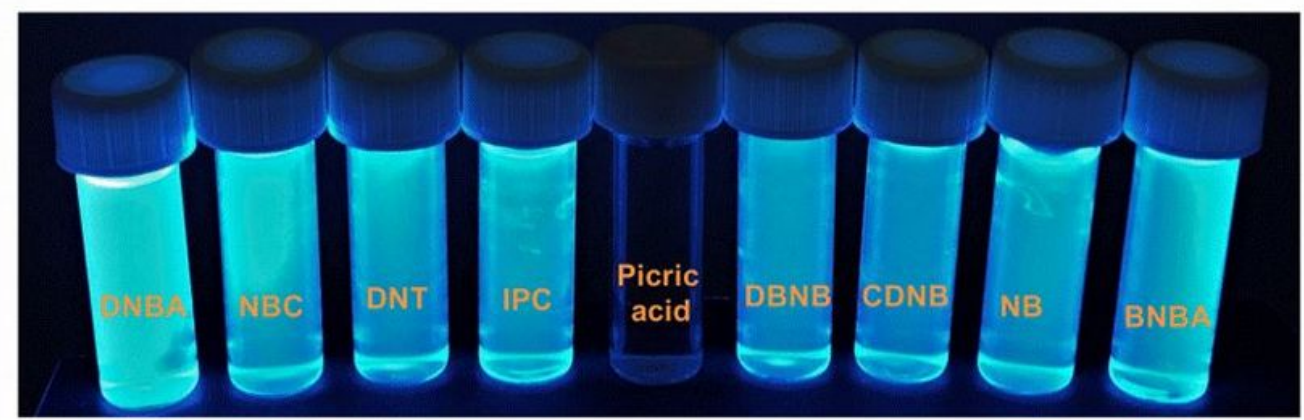

(c)

\section{Figure 1}

Emission responses of IPC $(50 \mu \mathrm{M})(\mathrm{a})$ with different nitro aromatic explosives (NBC, DNBA, BNBA, DNT, CDNB, DBNB, NB and PA) and the inset shows the pictorial images of the color for IPC in the deficiency and absence of PA and (b) with increasing amounts of PA [0.00-20.0 eqv.] in H2O/ACN (5/95, v/v) media $(\lambda \mathrm{ex}=330 \mathrm{~nm}, \lambda \mathrm{em}=408 \mathrm{~nm})$ and (c) an illustration and photograph of fluorescence responses 


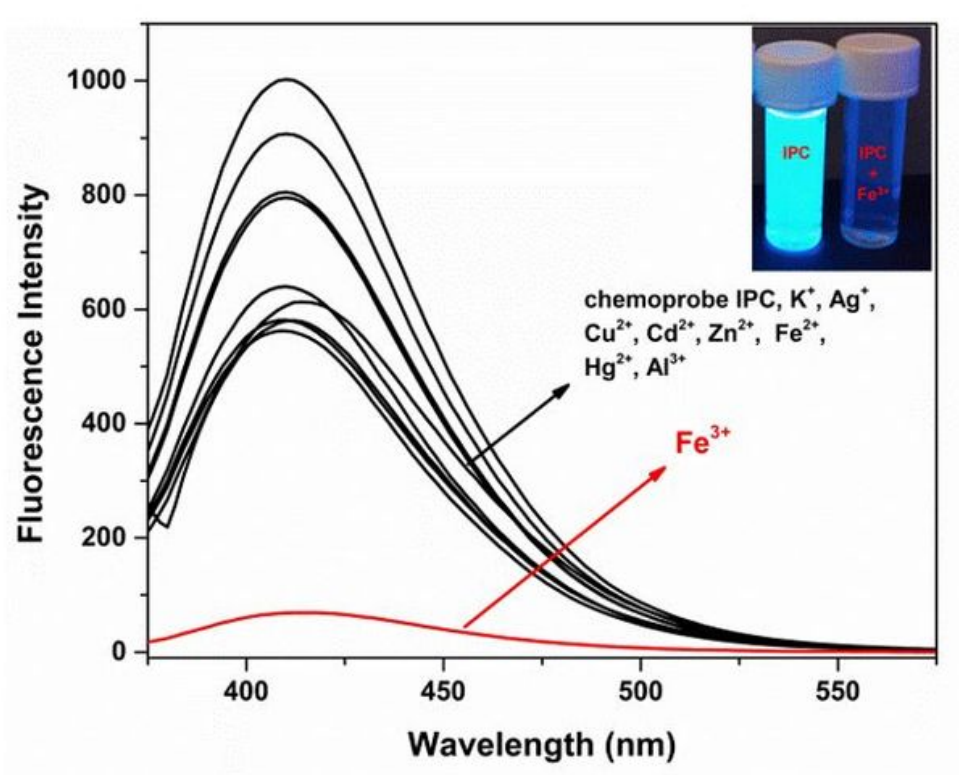

(a)

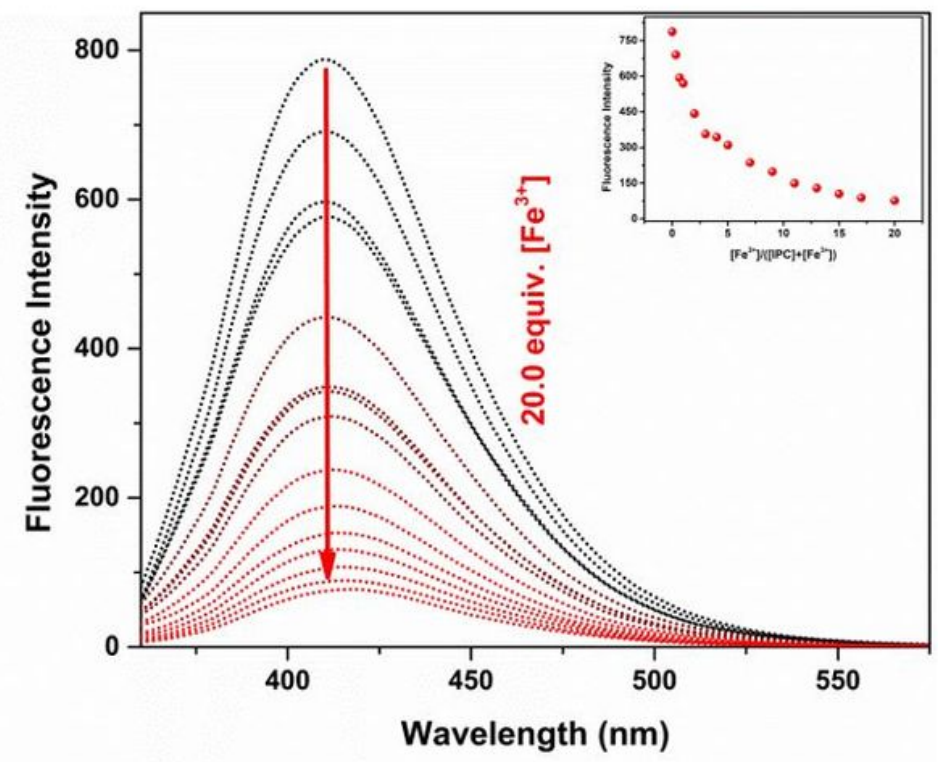

(b)

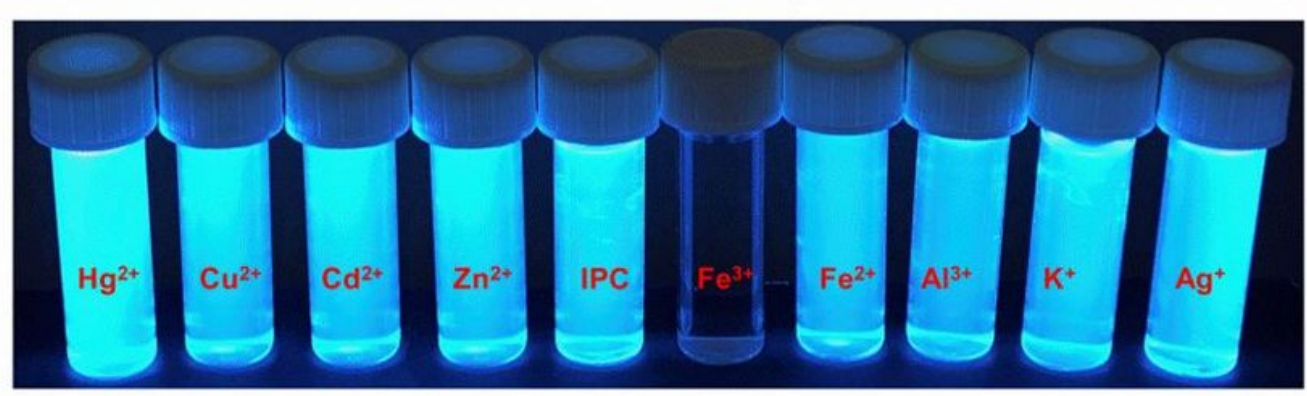

(c)

\section{Figure 2}

Emission responses of IPC $(50 \mu \mathrm{M})(\mathrm{a})$ with different metal ions $(\mathrm{K}+, \mathrm{Ag}+, \mathrm{Cu} 2+, \mathrm{Cd} 2+, \mathrm{Zn} 2+, \mathrm{Fe} 2+, \mathrm{Hg} 2+$, $\mathrm{Al} 3+$ and $\mathrm{Fe} 3+$ ) and the inset shows the pictorial images of the color for IPC in the deficiency and absence of Fe3+and (b) with increasing amounts of Fe3+ [0.00-20.0 eqv.] in H2O/ACN (5/95, v/v) media $(\lambda e x=330 \mathrm{~nm}, \lambda e m=408 \mathrm{~nm})$ and (c) an illustration and photograph of fluorescence responses 

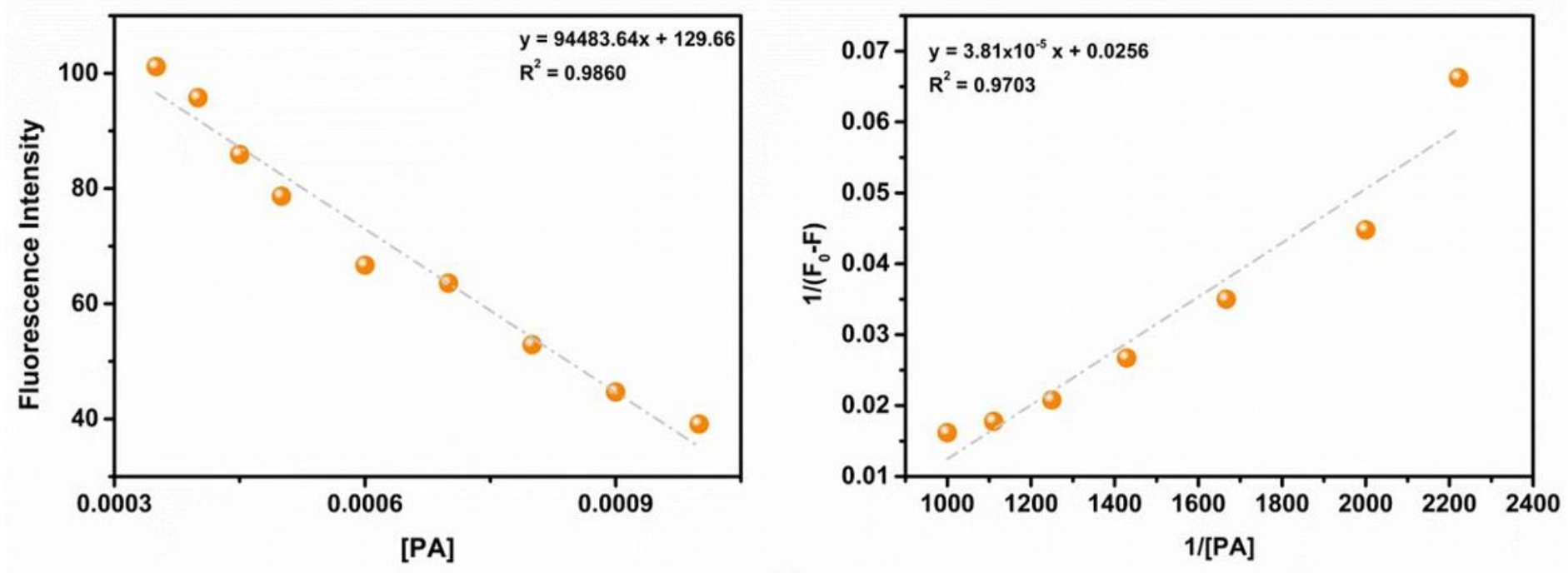

(a)
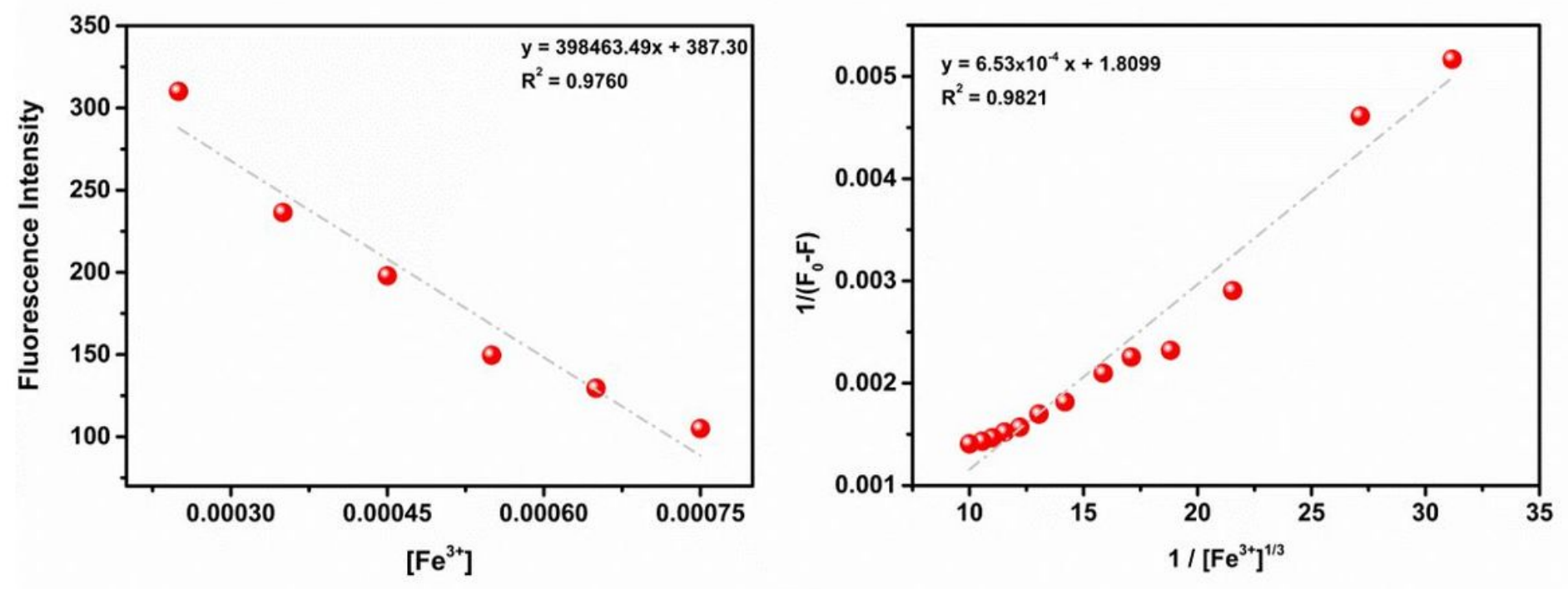

(b)

\section{Figure 3}

Plots of the fluorescence intensity of chemoprobe IPC versus (a) PA and (b) Fe3+ concentrations and Benesi-Hildebrand of the chemoprobe IPC towards PA and Fe3+ in H2O/ACN $(5 / 95, v / v)$ media $(\lambda e x=330$ $\mathrm{nm}, \lambda \mathrm{em}=408 \mathrm{~nm}$ ) 


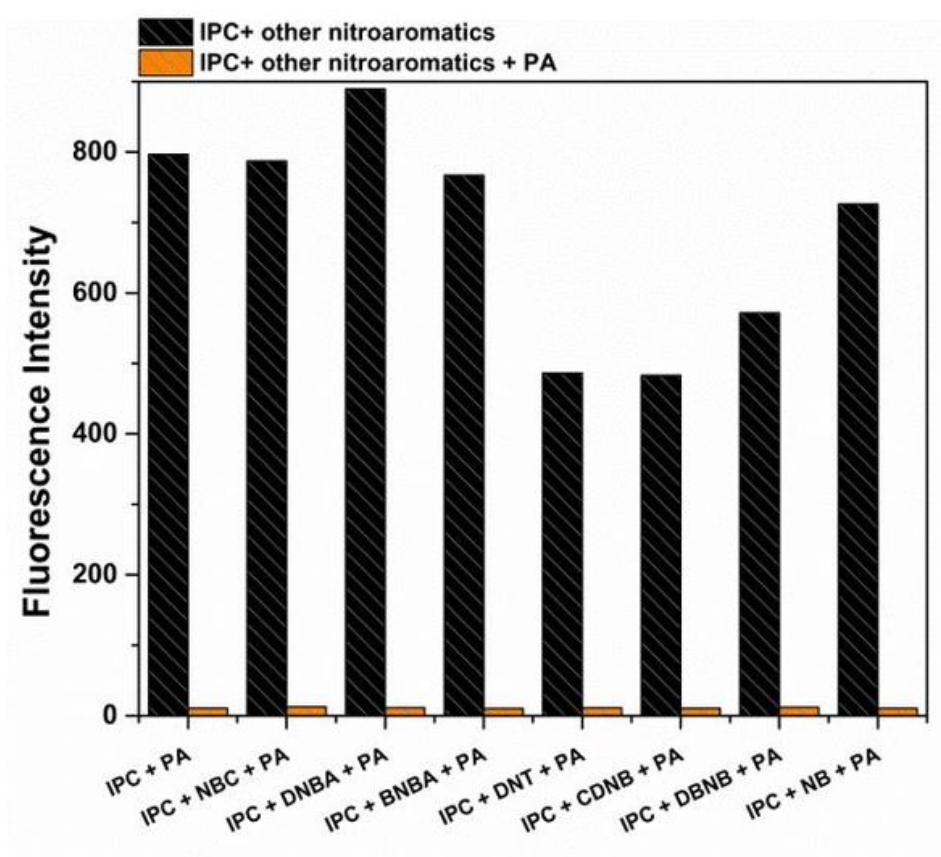

(a)

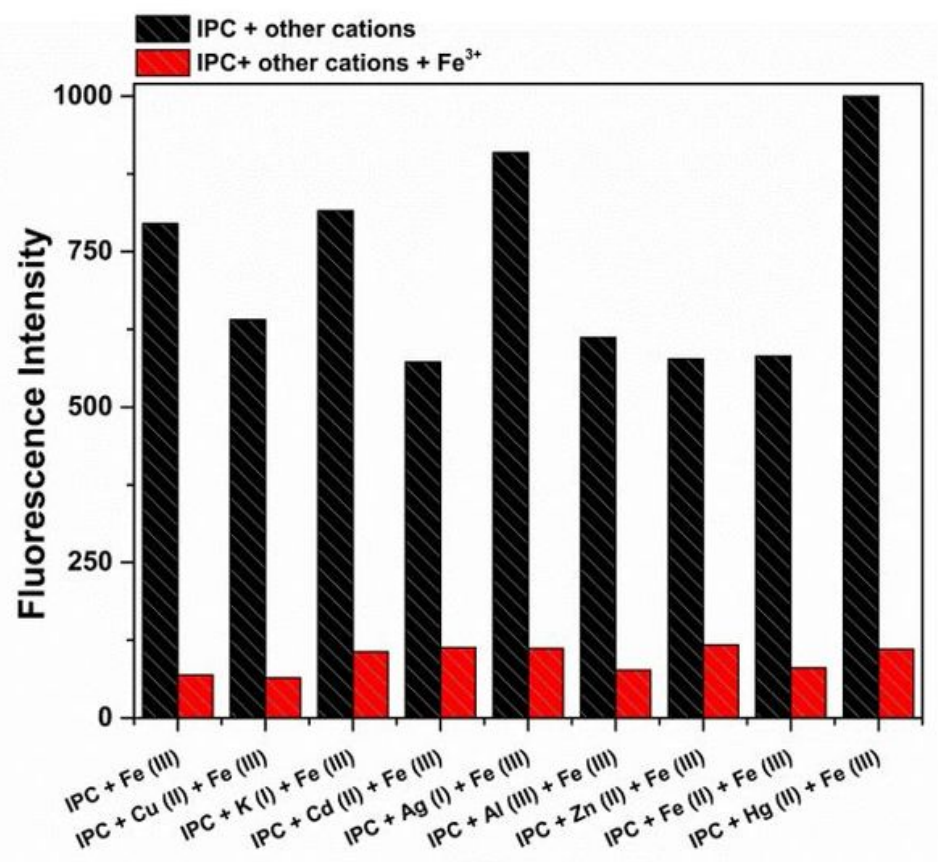

(b)

\section{Figure 4}

Relative emission intensity alterations (selectivity studies) of IPC $(50 \mu \mathrm{M})$ in the presence of higher concentrations of common interfering (a) nitro aromatic explosives (NBC, DNBA, BNBA, DNT, CDNB, DBNB, NB and PA) and (b) metal ions ( $\mathrm{K}+, \mathrm{Ag}+, \mathrm{Cu} 2+, \mathrm{Cd} 2+, \mathrm{Zn} 2+, \mathrm{Fe} 2+, \mathrm{Hg} 2+, \mathrm{Al} 3+$ and $\mathrm{Fe} 3+)$ in $\mathrm{H} 2 \mathrm{O} / \mathrm{ACN}(5 / 95, \mathrm{v} / \mathrm{v})$ media $(\lambda \mathrm{ex}=330 \mathrm{~nm}, \lambda \mathrm{em}=408 \mathrm{~nm})$ 


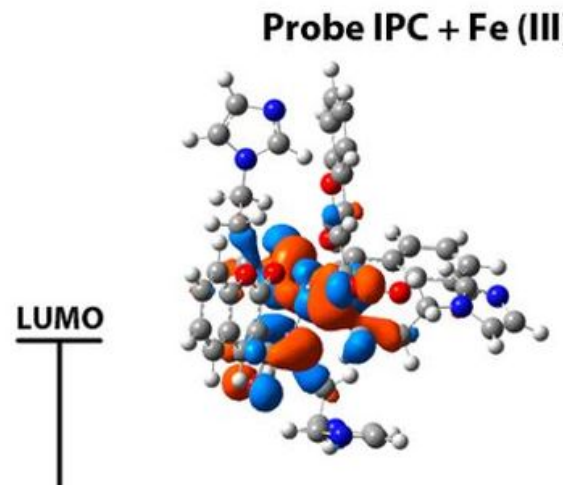

Probe IPC

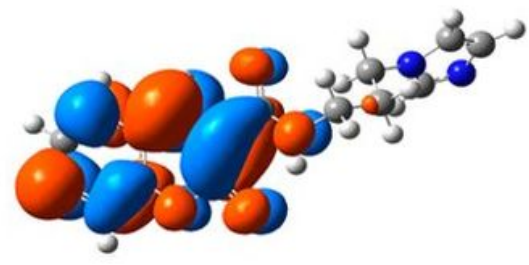

LUMO

$-2.52 \mathrm{eV}$

$$
3.32 \mathrm{eV}
$$

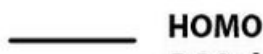

$-5.84 \mathrm{eV}$

LUMO

$-7.44 \mathrm{eV}$ HOMO

$-8.14 \mathrm{eV}$

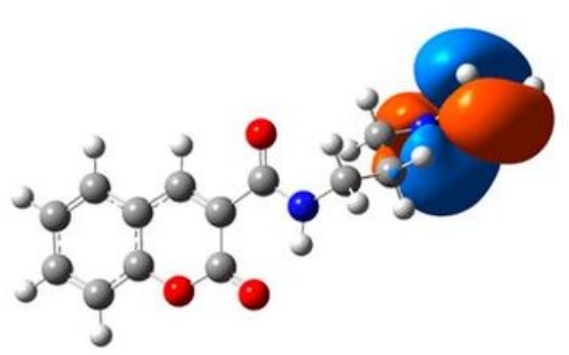

Probe IPC + Picric Acid

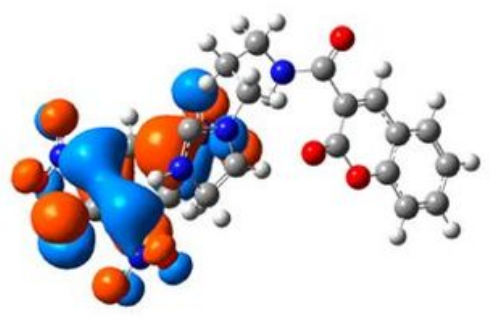

LUMO

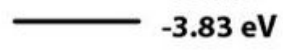

$2.19 \mathrm{eV}$
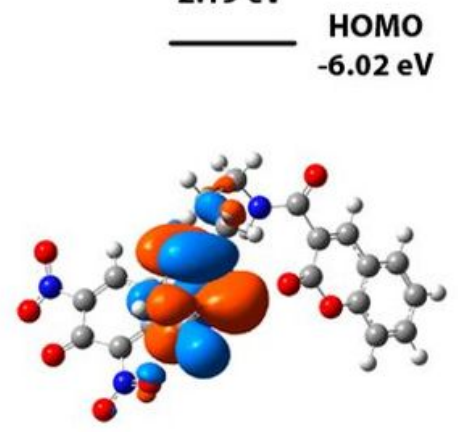

Figure 5

The findings of IPC, IPC-PA and IPC-Fe3+ by DFT/B3LYP/LANL2DZ

\section{Supplementary Files}

This is a list of supplementary files associated with this preprint. Click to download.

- scheme1.jpg

- scheme2.jpg 